\title{
LIVER
}

\section{Expression of somatostatin receptors in normal and cirrhotic human liver and in hepatocellular carcinoma}

\author{
H Reynaert, K Rombouts, A Vandermonde, D Urbain, U Kumar, P Bioulac-Sage, M Pinzani, \\ J Rosenbaum, A Geerts
}

See end of article for authors' affiliations

Correspondence to: Dr H Reynaert, Department of GastroenterologyHepatology, University Hospital Vrije Universiteit Brussel (AZ-VUB), Laarbeeklaan 101,B-1090 Brussels, Belgium: Hendrik.Reynaert@ az.vub.ac.be

Accepted for publication 1 February 2004
Background: Somatostatin analogues have been used with conflicting results to treat advanced hepatocellular carcinoma (HCC). The aim of this study was to investigate expression of somatostatin receptor (SSTR) subtypes in human liver, and to examine the effect of selective SSTR agonists on proliferation, apoptosis, and migration of hepatoma cells (HepG2, HuH7) and hepatic stellate cells (HSCs). Methods: Expression of SSTRs in cell lines, normal and cirrhotic liver, and HCC was examined by immunohistochemistry and reverse transcription-polymerase chain reaction. Effects of SSTR agonists on proliferation and apoptosis of tumour cells and HSCs were assessed by the 5-bromo-2' deoxyuridine and TUNEL methods, respectively. The influence of SSTR agonists on migration was investigated using Boyden chambers.

Results: In normal liver, both hepatocytes and HSCs were negative for all five SSTRs. Cirrhotic liver and HCC as well as cultured hepatoma cells and HSCs expressed all five SSTRs, both at the protein and mRNA levels, except for HuH7 cells which did not immunoreact with SSTR3. None of the agonists influenced proliferation or apoptosis. However, compared with untreated cells, L-797,591, an SSTR1 agonist, reduced migration of HepG2, HuH7, and HSCs significantly to $88(7) \%(p<0.05), 83(11) \%(p<0.05)$, and $67(13) \%(p<0.01)$, respectively.

Conclusions: Cirrhotic liver and HCC express SSTRs. Although the somatostatin analogues used in this study did not affect proliferation and apoptosis, stimulation of SSTR1 may decrease invasiveness of HCC by reducing migration of hepatoma cells and/or HSCs. Clinical trials evaluating somatostatin analogues for the treatment of HCC should take these findings into account.
$\mathrm{H}$ epatocellular carcinoma (HCC) is one of the most feared complications of cirrhosis. It is a prevalent malignant tumour with an extremely poor prognosis Radical curative surgery is performed in only a minority of patients with HCC. ${ }^{12}$ Local treatment (for example, transcatheter arterial embolisation, radio frequency ablation, or percutaneous ethanol injection) is a therapeutic alternative in some cases. However, for large, diffuse, multifocal, or metastatic HCC, no standard therapy is available. ${ }^{12}$ Because chemotherapy is associated with low response rates, other drugs with immunomodulatory and antiangiogenic properties are under investigation. ${ }^{2}$

The ability of somatostatin to block hormone secretion led to the application of long acting somatostatin analogues for the treatment of endocrine tumours. However, as well as neuroendocrine tumours, some solid cancers also express somatostatin receptors (SSTR). ${ }^{3}$ In vitro receptor autoradiography and radioligand binding studies have demonstrated that some HCCs also bear SSTRs. ${ }^{5} 6$

Results of studies assessing the efficacy of somatostatin analogues on tumour progression and survival in humans with HCC are conflicting. In some studies, octreotide was found to improve significantly survival of patients with unresectable $\mathrm{HCC}^{578}$ while these results were not confirmed by others. ${ }^{9-11}$ Furthermore, a beneficial effect on tumour progression was reported ${ }^{8}$ whereas in another study no significant effect was found. ${ }^{7}$ The only two placebo controlled randomised trials did not show significant benefit of octreotide on patient survival and tumour progression. ${ }^{9}{ }^{12}$ On the other hand, quality of life and/or performance status were reported to be increased and treatment was generally well tolerated, without major side effects. ${ }^{711}$
Somatostatin acts through five $\mathrm{G}$ protein coupled receptors (SSTR1-5). Pharmacological studies have shown that all subtypes bind to somatostatin 14 with high affinity whereas the long acting analogues octreotide, lanreotide, and vapreotide have high affinity for SSTR2 and SSTR5, intermediate affinity for SSTR3, and almost no affinity for SSTR1 and $4 .{ }^{3}$ Whereas the majority of solid tumours bind octreotide with high affinity, some bind octreotide with low affinity. Furthermore, activation of different SSTRs results in different biological effects, emphasising the importance of identifying the exact SSTR subtype before initiating clinical trials with somatostatin analogues. ${ }^{4}$

Therefore, the aim of the present study was to investigate expression of SSTR subtypes in human liver and to study the effects of SSTR subtype specific agonists on proliferation, apoptosis, and migration of hepatoma cell lines and hepatic stellate cells (HSCs).

\section{MATERIALS AND METHODS}

Tissues

Human liver tissue was obtained from surgical resection specimens at the time of partial hepatectomy or transplantation. No surgical procedures other than those planned were performed and no extra tissue was removed for the purpose of this study. Liver samples were obtained from patients with HCC and associated cirrhosis. Aetiology of cirrhosis was

\footnotetext{
Abbreviations: $\alpha$-SMA, $\alpha$ smooth muscle actin; BrdU, 5- bromo-2' deoxyuridine; DMEM, Dulbecco's modified Eagle's medium; HCC, hepatocellular carcinoma; HGF, hepatocyte growth factor; HSCs, hepatic stellate cells; PDGF, platelet derived growth factor; PDGFR- $\beta$, platelet derived growth factor receptor $\beta$; RT-PCR, reverse transcriptionpolymerase chain reaction; SSTR, somatostatin receptor
} 
Table 1 Characteristics of the antibodies used for immunohistochemistry

\begin{tabular}{llll}
\hline Antibody & Type & Dilution & Source \\
\hline SSTR1 & Rabbit & $1 / 200$ & Courtesy YC Patel \\
SSTR2 & Rabbit & $1 / 200$ & Courtesy YC Patel \\
SSTR3 & Rabbit & $1 / 200$ & Courtesy YC Patel \\
SSTR4 & Rabbit & $1 / 200$ & Courtesy YC Patel \\
SSTR5 & Rabbit & $1 / 200$ & Courtesy YC Patel \\
$\alpha$-SMA & Mouse & $1 / 400$ & Sigma, Bornem, Belgium \\
PDGFR- $\beta$ & Mouse & $1 / 100$ & R\&D ImmunoSource, Halle-Zoersel, Belgium \\
Secondary antibody & Antirabbit & $1 / 100$ & Amersham Biosciences Europe, Roosendaal, Netherlands. \\
Secondary antibody & Antimouse & $1 / 50$ & Sigma, Bornem, Belgium \\
\hline \multicolumn{2}{l}{ SSTR, somatostatin receptor; PDGFR- $\beta$, platelet derived growth factor receptor $\beta}$.
\end{tabular}

alcohol in three patients and hepatitis $\mathrm{C}$ in three patients. Samples from HCC as well as from surrounding cirrhotic liver were collected. In three patients, normal liver tissue was obtained at a site distant from resected solitary benign liver lesions. Specimens were processed in the pathology department (Hôpital Pellegrin, Bordeaux) and the laboratory for molecular liver cell biology (Vrije Universiteit Brussels). Samples were immediately frozen in either liquid nitrogen cooled isopentane for immunohistochemistry or directly in liquid nitrogen for reverse transcription-polymerase chain reaction (RT-PCR) experiments, and stored at $-80^{\circ} \mathrm{C}$ until used. HepG2 and HuH7 HCC cell lines were cultured in Dulbecco's modified Eagle's medium (DMEM) supplemented with $10 \%$ fetal calf serum. Human HSCs were isolated and cultured as described previously. ${ }^{13}$

\section{Immunohistochemistry}

For immunodetection of human SSTRs, subtype specific antibodies were used. These antibodies were developed and validated for immunohistochemistry in human tissue and were shown to be specific. ${ }^{14}$ Double staining immunohistochemistry was performed as described previously, with minor modifications..$^{15}$ In short, $8-10 \mu \mathrm{m}$ tissue sections were cut and fixed in methanol for 10 minutes at $-20^{\circ} \mathrm{C}$. Non-specific binding was blocked by incubating sections with $2 \%$ albumin/phosphate buffered saline. The sections were incubated with a combination of primary antibodies to one of the five SSTRs and antibodies to platelet derived growth factor receptor $\beta$ (PDGFR- $\beta$ ) or $\alpha$ smooth muscle actin ( $\alpha$-SMA). Sources, types, and dilutions of all antibodies are summarised in table 1. Peroxidase conjugated secondary antirabbit and alkaline phosphatase conjugated antimouse antibodies were added. Alkaline phosphatase was visualised with use of fast red TR/Naphtol AS-MX (Sigma-Aldrich, Bornem, Belgium). This reaction provided a red reaction product. Peroxidase was visualised by $3,3^{\prime}$-diaminobenzidine $/ \mathrm{H}_{2} \mathrm{O}_{2}$ enhanced by $\mathrm{Ni}^{2+}$ and $\mathrm{Co}^{2+}$ ions, resulting in a black reaction product. Cells reacting with both primary antibodies stained brownish. After staining for nuclei with haematoxylin (Harris, Sigma, Bornem, Belgium), sections were mounted in DePeX (Dako, Merelbeke, Belgium) and were studied using a Zeiss Axioplan microsope (Zeiss, Jena, Germany). To further investigate the presence of different SSTRs on distinct cell types, human HSCs and two HCC cell lines, HepG2 and HuH7 cells, were exposed to SSTR antibodies for immunohistochemistry. In the presence of culture medium, cells were seeded on Falcon culture slides (Becton Dickinson Labware, Meylan, France) at a density of 5000 HSCs, or $10000 \mathrm{HepG} 2$ or HuH7 cells per chamber. Cells were exposed to SSTR antibodies and peroxidase conjugated secondary anti-rabbit antibodies, as described above.

\section{PCR amplification}

RNA was extracted using the RNeasy mini extraction kit (QIAgen, Westburg, the Netherlands) according to the manufacturer's manual. RNA extracted from human pancreas was used as a positive control. ${ }^{14}$ A total of $187 \mathrm{ng}$ of RNA was reverse transcribed using the RT-PCR core kit (Perkin-Elmer, New Jersey, USA), as described previously. ${ }^{16}$ The reaction mixture $(2.5 \mu \mathrm{l})$ was used for PCR amplification. cDNA was first denatured at $94^{\circ} \mathrm{C}$ for 10 minutes followed by PCR for 35 cycles each consisting of a denaturation step $\left(94^{\circ} \mathrm{C}\right.$ for one minute), an annealing step $\left(69^{\circ} \mathrm{C}\right.$ for one minute), and a primer extension step $\left(72^{\circ} \mathrm{C}\right.$ for one minute). Finally, an elongation step $\left(72^{\circ} \mathrm{C}\right.$ for 10 minutes) was performed. In table 2, the primers used to amplify the five known SSTR subtypes are summarised. To check for contamination with chromosomal DNA, $\beta$-actin was amplified as described previously. ${ }^{17}$ Specificity of all PCR products was confirmed by automatic sequencing using the ABI prism 310 (Perkin Elmer).

\section{BrdU proliferation assay}

To elucidate effects of somatostatin on tumour progression, SSTR subtype specific agonists were used: L-797,591 (SSTR1 agonist), L-779,976 (SSTR2 agonist), L-796,778 (SSTR3 agonist), L-803,087 (SSTR4 agonist), and L-817,818 (SSTR5 agonist) (Merck Research Laboratories, Rahway, New Jersey, USA). These substances are non-peptide somatostatin agonists with a very high subtype specificity, except for L-817,818 which has affinity not only for SSTR5 but also some for SSTR1. Although these substances have been used in animal cells, they were designed and developed as agonists for human SSTRs. The affinity of the agonists was tested in

Table 2 Primers used to amplify the five somatostatin receptors (SSTRs)

\begin{tabular}{|c|c|c|c|}
\hline \multicolumn{2}{|c|}{ Receptor Forward primer } & \multirow{2}{*}{$\begin{array}{l}\text { Reverse primer } \\
\text { 5'-GCACGTAGCACAGGCAGATA-3' }\end{array}$} & \multirow{2}{*}{$\begin{array}{l}\text { Accession No } \\
\text { M } 81829\end{array}$} \\
\hline SSTRI & 5'-AGACGGCCACCAACATCTAC-3" & & \\
\hline SSTR2 & $5^{\prime}$-GACAAGCAATGCAGTCCTCA-3' & 5'-CTGTGTACCAAGCCCCAGAT-3' & AF 184174 \\
\hline SSTR3 & 5'-TCTGCTACCTGCTCATCGTG-3"' & 5'-TTGAAGCGGTAGGAGAGGAA-3' & M 96738 \\
\hline SSTR4 & 5'-AAGCTCATCAACCTGGGCGTG-3' & 5'-GGGTTCTGGTTGCAGGGCTTC-3' & XM 009594 \\
\hline SSTR5 & $5^{\prime}$-CTCTCTCTGGACCTTGTGCC-3" & 5'-ACGAGCAAACAGGTACGCTT-3' & U 18976 \\
\hline
\end{tabular}



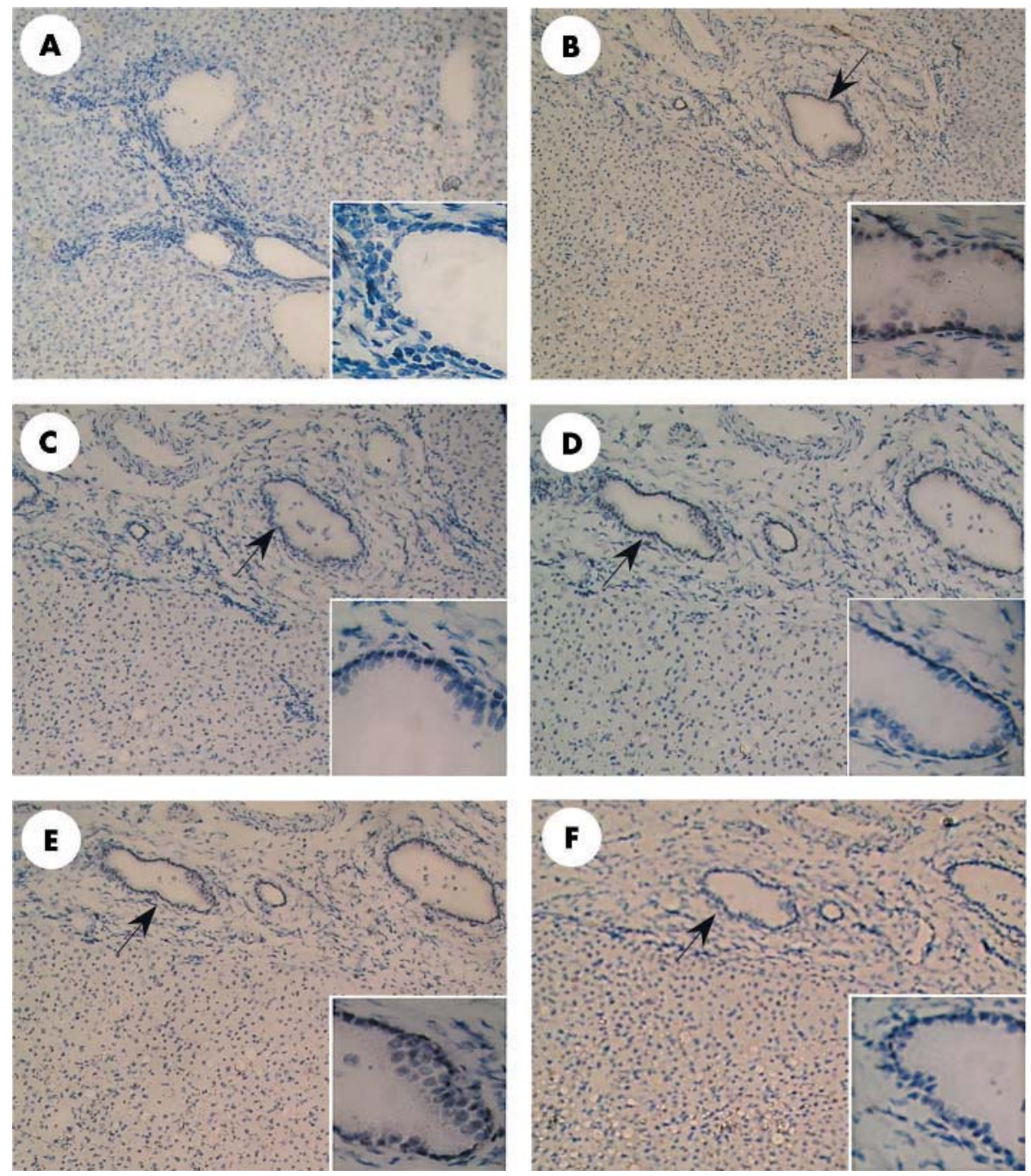

Figure 1 Representative immunohistochemical staining of normal human liver. The biopsy was taken in a patient with a benign liver tumour. (A) Negative control. Somatostatin receptor subtypes SSTR1-5 (B, C, D, E, and F, respectively) localised at bile ducts in portal tracts (arrows). Immunoreaction with SSTR2, 3, and 5 was less intense than for SSTR subtypes 1 and 4 . For all other cells, no immunoreaction was observed. Original magnification $100 \times$, inserts $400 \times$.

transfected CHO-Kl cells expressing each of the five human SSTRs. ${ }^{18}$ In addition to their specificity, these agonists have a prolonged half life. Biological effects of the agonists has been tested in several cell lines and these effects were SSTR subtype specific. ${ }^{19}$

Cell proliferation was measured by using the colorimetric 5-bromo-2' deoxyuridine (BrdU) cell proliferation ELISA (Boehringer, Mannheim, Germany), as described previously. ${ }^{20}$ After trypsinisation, HepG2, HuH7, and HSCs were plated in 96 well dishes (Falcon, Becton Dickinson Labware, Meylan, France) at a density of $15 \times 10^{3}, 15 \times 10^{3}$, and $6 \times 10^{3}$ cells per well, respectively. All cells were suspended in DMEM supplemented with $2 \%$ fetal calf serum. After 24 hours, media were renewed and cells exposed for another 24 hours to different concentrations of SSTR agonists $\left(10^{-12}\right.$ to $10^{-8} \mathrm{~mol} / \mathrm{l}$ ) in the presence of $10 \mu \mathrm{mol}$ BrdU. Platelet derived growth factor (PDGF-BB $10 \mathrm{ng} / \mathrm{ml}$ ), a strong mitogen for HSCs ${ }^{21}$ was added to the medium of HSCs (R\&D Systems Europe, Abingdon, UK). In each experiment, all conditions were tested 10 times, and every experiment was performed in triplicate. To allow comparison of proliferation between different groups, results were expressed as percentages and compared with controls normalised to $100 \%$. Mean (SD) values were calculated for all groups.

\section{In situ cell death detection}

Somatostatin induced apoptosis was studied by the TUNEL reaction according to the manufacturer's instructions (In Situ Cell Death Detection Kit; Roche diagnostics, Belgium). After trypsinisation, HepG2, HuH7, and HSCs were plated in 96 well dishes at a density of $2.5 \times 10^{3}, 2.5 \times 10^{3}$, and $1 \times 10^{3}$ cells per well, respectively. All cells were suspended in DMEM supplemented with $2 \%$ fetal calf serum. As apoptosis has been attributed to stimulation of SSTR2 and 3, different concentrations $\left(10^{-12}\right.$ to $\left.10^{-6} \mathrm{~mol} / \mathrm{l}\right)$ of L-779,976 and L-796,778, agonists of SSTR 2 and 3, respectively, were studied. After 24 and 72 hours of treatment, apoptotic cells were counted and expressed as a percentage of total cells. Experiments were performed in triplicate.

\section{Cell invasion assay}

The influence of the five SSTR agonists on migration of the hepatoma cell lines and HSCs was investigated, as described previously, ${ }^{22}$ using Boyden invasion chambers with $8 \mu \mathrm{m}$ pore size filters coated with Matrigel basement membrane matrix (Falcon, Becton Dickinson Labware, Bedford, Massachusetts, USA). PDGF-BB is a very strong chemoattractant for human HSCs $^{21}$ whereas hepatocyte growth factor (HGF) increases the invasiveness of HepG2 and HuH7 tumour cells. ${ }^{22}$ To 

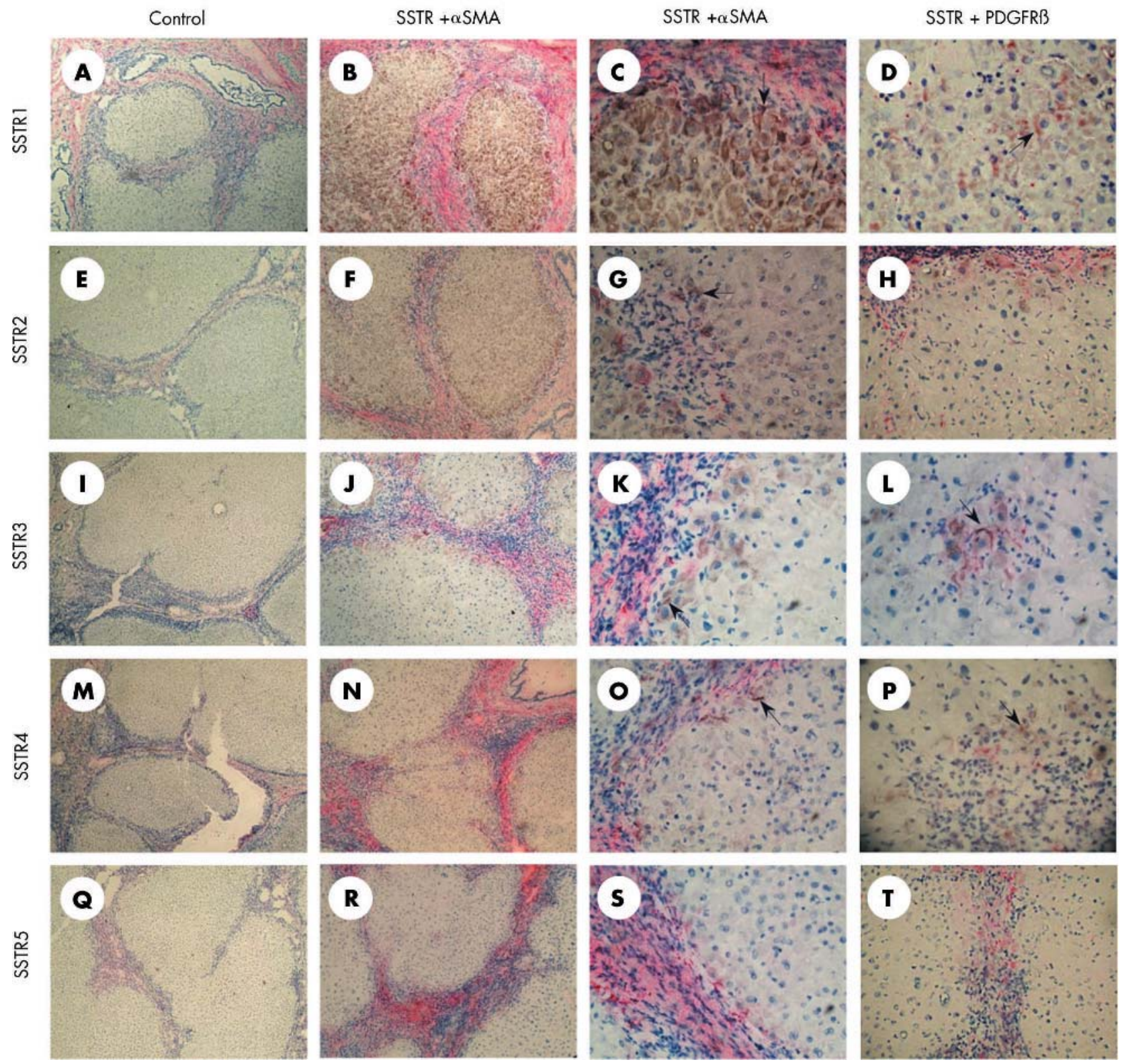

Figure 2 Expression of somatostatin receptors (SSTRs) in cirrhosis. All samples are from the same patient and were processed under the same conditions. Liver tissue was stained with haematoxylin-eosin and immunohistochemistry. The first column represents the negative controls of SSTR1 (A), SSTR2 (E), SSTR3 (I), SSTR4 (M), and SSTR5 (Q). In columns 2 and 3, double staining immunohistochemistry with $\alpha$ smooth muscle actin ( $\alpha$-SMA) and SSTR1 $(B, C)$, SSTR2 $(F, G)$, SSTR3 $(J, K)$, SSTR4 $(N, O)$, and SSTR5 $(R, S)$ is shown. We observed intense immunoreaction of SSTR1 and 2 with hepatocytes whereas immunoreaction with SSTR3, 4, and 5 was less clear. At the interface between the fibrous septa and the cirrhotic nodules, cells which double stained for $\alpha$-SMA and SSTR1-4 (C, G, K, O) (arrows) but not SSTR5 (S) can be seen. Again, immunoreaction was most intense with SSTR subtypes 1 and 2 . In the last column, double staining immunohistochemistry with platelet derived growth factor receptor $\beta$ (PDGFR- $\beta$ ) and SSTR1 (D), SSTR2 (H), SSTR3 (L), SSTR4 (P), and SSTR5 (T) is represented. Some hepatic stellate cells within cirrhotic nodules reacted with PDGFR- $\beta$ and SSTR1 and 3 (arrows), but not with SSTR2, 4, and 5. Original magnification $100 \times$ for column 1, 200 × for column 2, and $400 \times$ for columns 3 and 4).

investigate the possibility that somatostatin inhibits PDGF$\mathrm{BB}$ induced migration of HSCs or HGF induced migration of HepG2 and HuH7, cells were seeded in the upper well of Boyden chambers in the presence of PDGF-BB or HGF in the lower chamber. In these experiments, $2.5 \times 10^{4}$ hepatoma cells or HSCs were seeded onto the filter. HGF $20 \mathrm{ng} / \mathrm{ml}$ (R\&D Systems Europe, Abingdon, UK) was added to the lower chamber when hepatoma cells were seeded in the upper chamber, or PDGF-BB $10 \mathrm{ng} / \mathrm{l}$ was added when HSCs were present in the upper chamber. Subsequently, $10^{-9} \mathrm{~mol} / \mathrm{l}$ of SSTR agonists were added to the cells in the upper chamber. After 12 and 48 hours for experiments with HSCs and hepatoma cells, respectively, cells in the upper chamber were wiped with a cotton swab, and the filters were fixed in methanol and stained with haematoxylin. Cells invading the lower surface of the filter were counted in 10 high power fields using a Zeiss Axioplan microscope. Results were expressed as a percentage, relative to controls normalised to $100 \%$. Experiments were performed in triplicate, except for controls and experiments with L-797,591 (agonist of SSTRl) which were performed six times. 

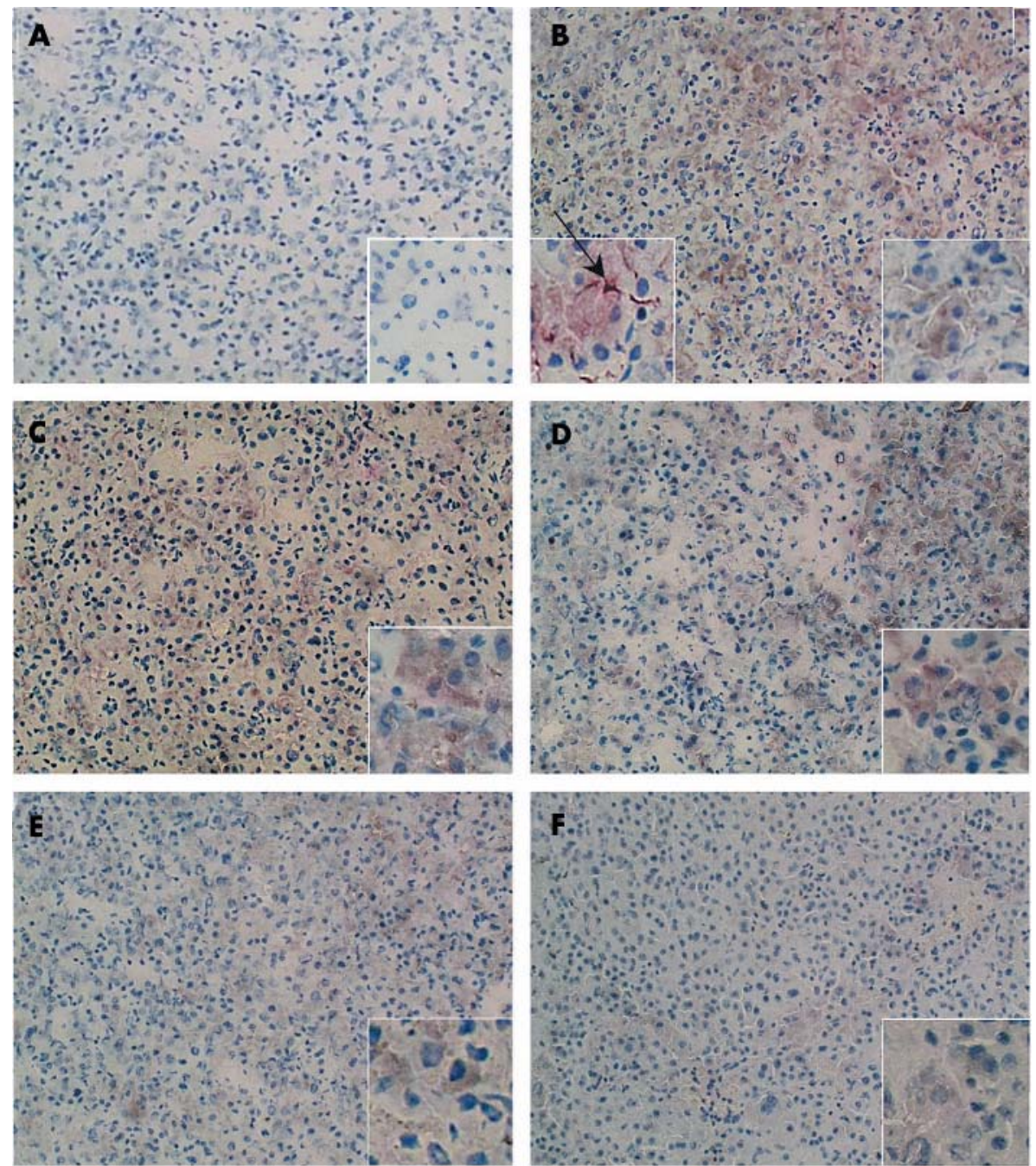

Figure 3 Immunohistochemistry of somatostatin receptors (SSTRs) in hepatocellular carcinoma. (A) Negative control. (B-F) Double staining immunohistochemistry with $\alpha$ smooth muscle actin ( $\alpha$-SMA) and SSTR 1-5 in the same patient. We observed intense immunoreaction with SSTR 1-4, and to a lesser degree with SSTR5. Within the tumour, double positive cells were seen (arrow, B insert). These cells are clearly activated hepatic stellate cells. Original magnification $100 \times$, inserts $400 \times$.

\section{Statistical analysis}

One way analysis of variance (ANOVA) with Bonferroni's correction for multiple comparisons and the Mann-Whitney test were used when appropriate. Results are presented as means (SD). A p value of $<0.05$ was considered statistically significant. Analysis was performed using Instat software (GraphPad software inc., San Diego, California, USA).

\section{RESULTS}

\section{Immunohistochemistry}

Using well validated specific antibodies against the five recognised SSTRs, we were able to localise the different SSTRs in sections of normal liver (fig 1), cirrhosis (fig 2), and HCC (fig 3). Expression of the various receptors varied between different specimens and cells (table 3 ).

\begin{tabular}{|c|c|c|c|c|c|}
\hline & SSTR I & SSTR2 & SSTR3 & SSTR4 & SSTR5 \\
\hline \multicolumn{6}{|l|}{ Normal liver } \\
\hline Hepatocytes & $0 / 3$ & $0 / 3$ & $0 / 3$ & $0 / 3$ & $0 / 3$ \\
\hline Bile ducts & $3 / 3$ & $2 / 3$ & $3 / 3$ & $3 / 3$ & $1 / 3$ \\
\hline Blood vessels & $2 / 3$ & $0 / 3$ & $0 / 3$ & $0 / 3$ & $0 / 3$ \\
\hline Sinusoids & $0 / 3$ & $0 / 3$ & $0 / 3$ & $0 / 3$ & $0 / 3$ \\
\hline \multicolumn{6}{|l|}{ Cirrhosis } \\
\hline Hepatocytes & $6 / 6$ & $4 / 6$ & $4 / 6$ & $4 / 6$ & $4 / 6$ \\
\hline Interface HSC & $6 / 6$ & $4 / 6$ & $4 / 6$ & $4 / 6$ & $4 / 6$ \\
\hline Lobular HSC & $4 / 6$ & $0 / 6$ & $1 / 6$ & $0 / 6$ & $0 / 6$ \\
\hline \multicolumn{6}{|l|}{ HCC } \\
\hline Tumour cells & $5 / 6$ & $4 / 6$ & $3 / 6$ & $3 / 6$ & $3 / 6$ \\
\hline Myofibroblasts & $2 / 6$ & $2 / 6$ & $1 / 6$ & $0 / 6$ & $0 / 6$ \\
\hline
\end{tabular}




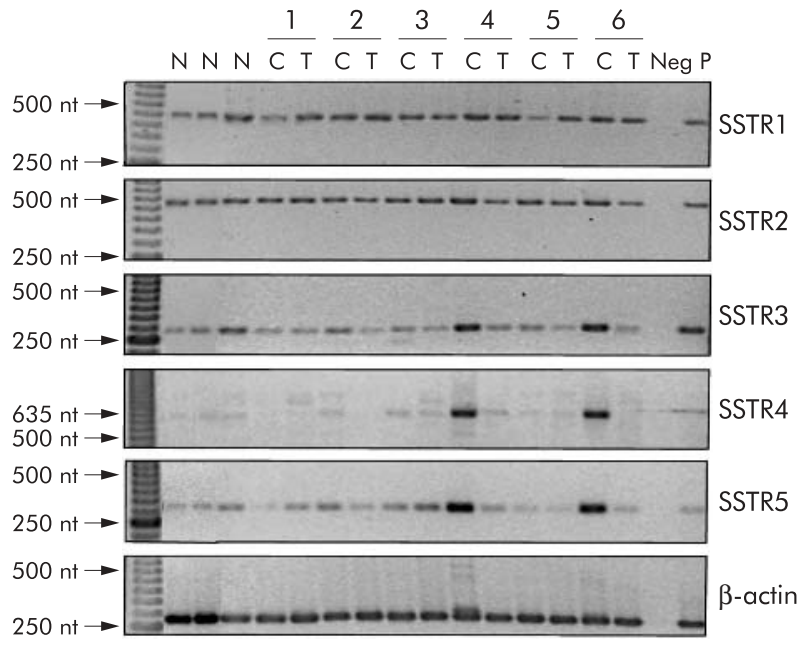

Figure 4 Expression of somatostatin receptor (SSTR) subtype 1-5 mRNA in human liver samples. From six patients (1-6), both cirrhotic (C) as well as tumoral (T) tissue was tested. Normal liver (N) from three different patients is represented in lanes 1-3. Human pancreas $(P)$ was used as a positive control and water as a negative (Neg) control. Patients 1,2 , and 6 had hepatitis $C$ related cirrhosis whereas patients 3,4 , and 5 had alcoholic cirrhosis. PCR reactions were performed on CDNA derived from $0.1875 \mu \mathrm{g}$ PolyA ${ }^{+}$RNA for 35 cycles using SSTR subtype specific primers. Primers amplified only fragments corresponding to SSTR subtypes 1-5. $\beta$-Actin primers were used as a control to check for genomic DNA contamination. This reverse transcription-polymerase chain reaction is not quantitative and thus only statements on the presence, but not on the quantity, of mRNA can be made. Samples in lanes 1 and 2 were obtained from different gels.

In fig 1 , normal liver is presented. Hepatocytes and sinusoidal cells did not stain for any of the five receptors. Cholangiocytes, on the other hand, consistently expressed SSTR subtypes 1, 3, and 4. Immunoreaction with SSTR subtypes 1 and 4 was more intense than with SSTR subtypes 2,3 , and 5 which were detected in, respectively, two, three, and one of the three analysed specimen. Furthermore, a weak immunoreaction of SSTRI with endothelial cells of a small number of small arteries was found (not shown).

In cirrhotic liver, expression of SSTRs significantly changed compared with normal liver. Hepatocytes within cirrhotic nodules expressed SSTR1 (fig 2B, C), and in $4 / 6$ of the examined specimens, specimens also expressed SSTR2 (fig 2F, G), SSTR3 (fig 2J, K), SSTR4 (fig 2N, O), and SSTR5 (fig 2R, $S)$. In most of the studied cases, we also found cells which double stained for all five SSTRs and $\alpha$-SMA. These cells, clearly activated HSCs, were located at the interface of septa and cirrhotic nodules (fig 2C, G, K, O). In some specimens, we observed HSCs within hepatic nodules that stained for PDGFR- $\beta$ and SSTR1 (fig 2D) or SSTR3 (fig 2L).
In fig 3, immunohistochemistry for HCC is presented. Most of the tumours stained with SSTR subtypes 1 and 2 whereas $50 \%$ reacted with SSTR subtypes 3, 4, and 5 (table 3 ). In some tumours, non-tumoral cells double stained for $\alpha$-SMA and SSTR subtypes 1, 2, and 3 (fig 3B, table 3 ).

To verify the results of double staining immunohistochemistry, isolated cell lines were exposed to the different SSTR antibodies. Human HSCs were positive for all five SSTRs although immunoreaction with SSTR3 was less intense. Similarly, HepG2 expressed the five SSTR subtypes, again less clearly SSTR3. Finally, HuH7 reacted with all SSTRs, except for SSTR3 (data not shown).

\section{Presence of SSTR mRNA in normal liver, cirrhosis, and HCC}

Messenger RNA of the five SSTRs was detected both in normal and pathological liver tissue (fig 4). We identified a single band for all receptors, except SSTR4 for which three bands were found in some patients. Sequencing demonstrated that the middle band (635 nucleotides), which was most intense, corresponded to SSTR4. This was in agreement with the findings of Talme et al who used the same primers for SSTR4..$^{23}$ All investigated samples were definitely positive for SSTR subtypes 1 and 2. For these receptors, no important variations between different patients or between cirrhosis and tumour samples from the same patient were observed. Expression of mRNA of SSTR subtypes 3, 4, and 5 was almost undetectable in some patients whereas a significant band was observed in others. In two of six patients, surrounding cirrhotic tissue expressed SSTR4 and 5 mRNA more clearly than the tumour of these patients.

\section{Presence of mRNA in cell lines}

When examining expression of mRNA of the five SSTRs in different cell lines, we were able to demonstrate the presence of all receptors in HSCs, HepG2, and HuH7 cells (fig 5). In agreement with the results of liver tissue, a single band was demonstrated for SSTR subtypes 1, 2, 3, and 5 whereas multiple bands were found for SSTR4. Again, the middle band (635 nucleotides) was shown to correspond to SSTR4.

\section{Effect of SSTR agonists on proliferation of HCC cell lines and HSCs}

Proliferation of hepatoma cells and HSCs was stimulated with $2 \%$ fetal calf serum or PDGF-BB, respectively. As expected, PDGF-BB induced a marked increase in the proliferation of HSCs. ${ }^{21}$ Proliferation of hepatocellular carcinoma cell lines HepG2 and HuH7, and HSCs did not change in the presence of different concentrations of various SSTR agonists compared with cells treated with PDGF-BB alone (data not shown).

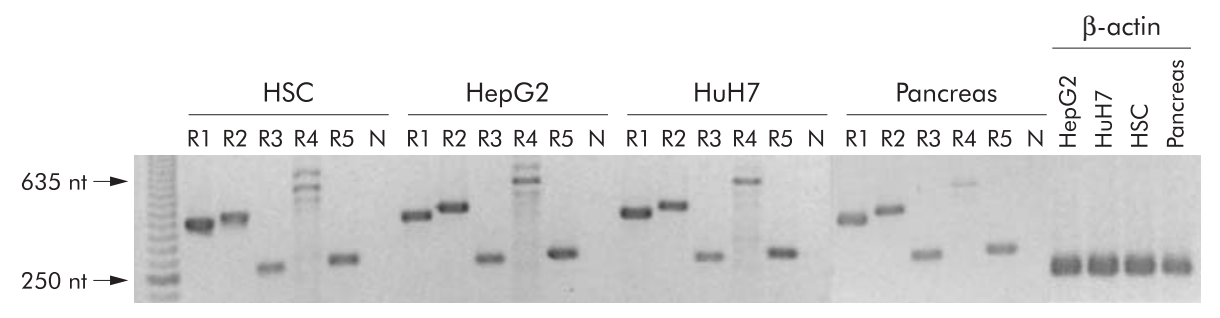

Figure 5 Polymerase chain reactions performed on cDNA derived from $0.1875 \mu \mathrm{g}$ mRNA extracted from human hepatic stellate cells (HSCs), and human hepatocellular carcinoma cell lines HepG2 and HuH7. Fragments corresponding to somatostatin receptor (SSTR) subtype 1 (R1), subtype 2 (R2), subtype 3 (R3), subtype 4 (R4), and subtype 5 (R5) after 35 cycles are shown. Primers to SSTR1, 2, 3, and 5 amplified only one fragment whereas the primer to SSTR4 amplified three fragments. Sequencing demonstrated that the most intense middle band (635 nucleotides) corresponded to SSTR4. Pancreas was used as a positive control tissue and water as a negative control (N). The quality of cDNA was confirmed by polymerase chain reaction of samples with primers to $\beta$-actin. 

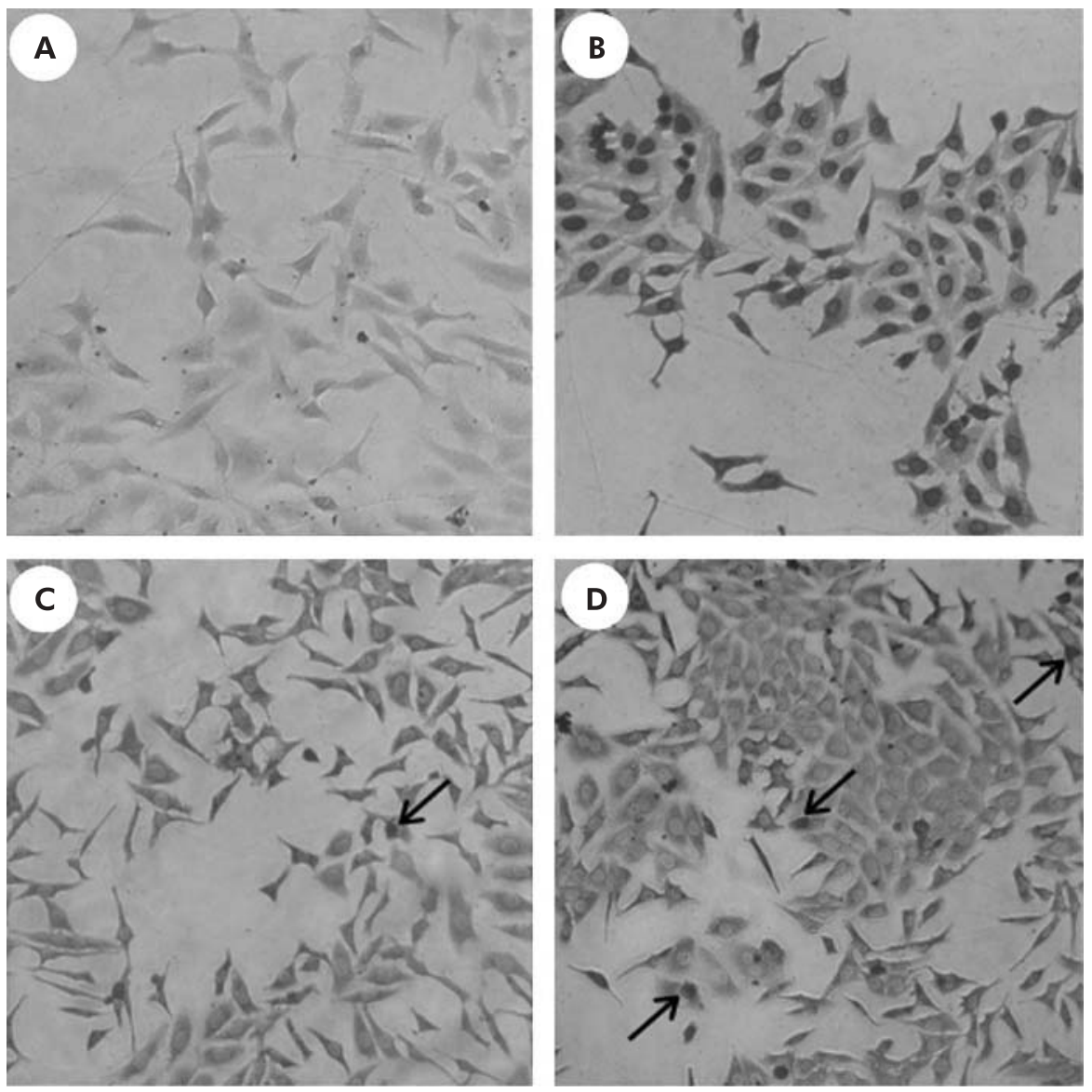

Figure 6 Influence of the somatostatin receptor (SSTR) subtype 2 and 3 agonists (L-779,976 and L-796,778) on apoptosis of HepG2 cells. (A) Negative control. (B) Positive control. After incubation of L-779, 976 (10 $\left.10^{-6} \mathrm{~mol} / \mathrm{l}\right)$ for 72 hours (C) and after incubation of L-796,778 (10-6 mol/l) for 72 hours (D). Some apoptotic cells were demonstrated (arrows). It is evident that none of the agonists induced significant apoptosis in our experimental set up. The same results were obtained after 24 hours with different concentrations of the somatostatin agonists and with Huh7 and hepatic stellate cells. Original magnification $\times 200$.

\section{Effects of SSTR2 and 3 on apoptosis of hepatoma cells and $\mathrm{HSCs}$}

In preliminary experiments, no apoptotic effects of somatostatin agonists were observed. As somatostatin induced apoptosis has been attributed to activation of SSTR2 and 3, definitive experiments were performed with these agonists. No effects were observed in any of the three cell lines after 24 hours. Even when cells were treated for 72 hours with L-779,976 or L-796,778, no difference in apoptosis between treated and untreated cells was detected (fig 6).

\section{Activation of SSTR 1 reduces migration of hepatoma cells and HSCs}

In the presence of chemotactic stimuli PDGF-BB or HGF in the lower part of the Boyden migration chamber, all three cell types migrated through the pores to the lower surface of the membrane (fig 7A). Among the five SSTR agonists tested, only addition of L-797,591 (SSTRl agonist) significantly reduced migration (fig 7B). Compared with untreated control cells, migration of HepG2, HuH7, and HSCs significantly decreased to $88(7) \%(\mathrm{p}<0.05), 83(11) \%(\mathrm{p}<0.05)$, and 67 (13)\% $(\mathrm{p}<0.01)$, respectively.

\section{DISCUSSION}

In this study, we have described expression of SSTR subtypes in normal human liver, in cirrhosis, and in HCC. Furthermore, we showed that migration of hepatoma cells and HSCs was reduced via activation of SSTR subtype 1 .
However, the subtype specific somatostatin agonists used in this study had no effect on proliferation or apoptosis.

Expression of SSTRs in human liver has not been studied in detail. In one study, SSTR2 was present in low amounts ${ }^{24}$ although in another study using northern blot analysis, no relevant amounts of mRNA for any of the five SSTRs could be detected. ${ }^{11}$ With the very sensitive RT-PCR technique, we were able to demonstrate the presence of all five SSTRs in normal human liver. By means of immunohistochemistry, we demonstrated that bile ducts, but not hepatocytes or sinusoids, immunoreacted with specific SSTR antibodies. Furthermore, SSTRI was present in the endothelial cells of some small blood vessels, which is in agreement with findings in normal extrahepatic human blood vessels. ${ }^{25}$ In a somatostatin 14/28 receptor binding study, levels of SSTRs were either absent, low, or very high in hepatitis and cirrhosis. ${ }^{5}$ We also found considerable variation in SSTR expression in cirrhosis. Receptor subtypes 1 and 2 were prominent in most of the studied samples but SSTR 3, 4, and 5 were clearly present in some and absent in other specimens. As we did not use a quantitative PCR method, we cannot draw firm conclusions on the variation in mRNA expression. However, care was taken to start with equal amounts of mRNA, as proven by amplification of $\beta$-actin mRNA. Additionally, immunohistochemistry results confirmed the observations. Upregulation of SSTRs during liver disease is in agreement with our previous findings that rat HSCs expressed SSTRs in diseased but not in normal liver. ${ }^{16}$ The 
A
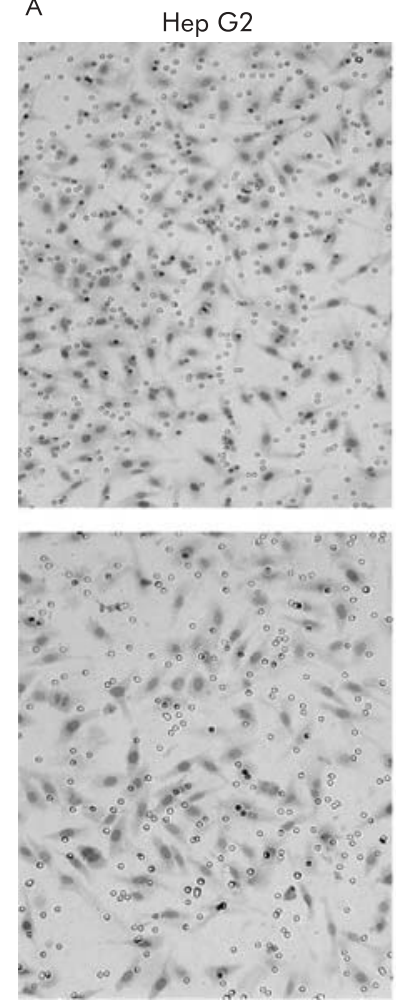

$\mathrm{HuH7}$
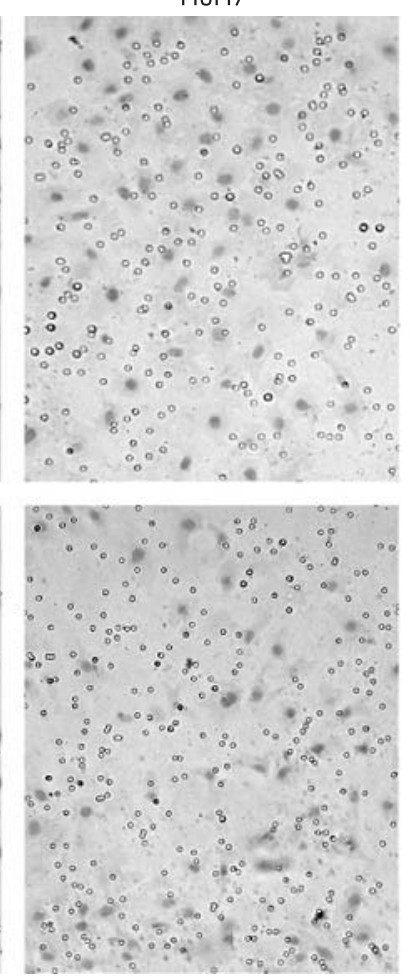

HSC
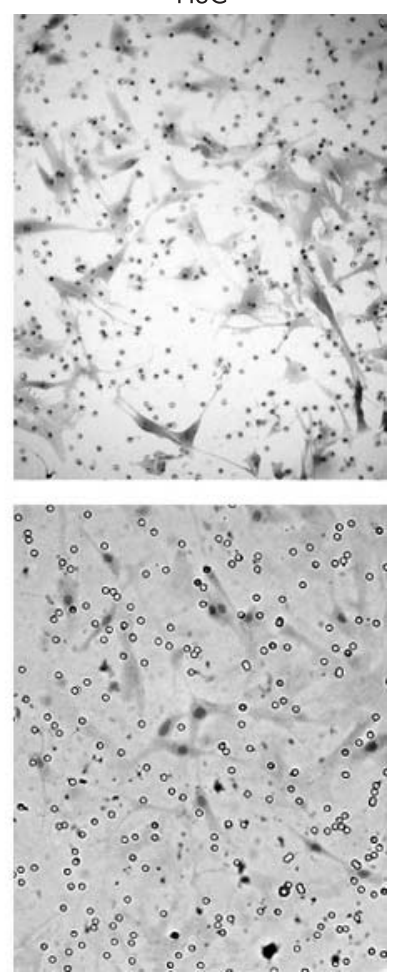

Figure 7 Effect of the somatostatin receptor (SSTR) subtype 1-5 specific agonists (L-797,591, L-779, 976, L-796,778, L-803,087, and L-817,818) on migration of HepG2 and HuH7 hepatoma cells and hepatic stellate cells (HSCs). Cells were seeded on a matrigel basement membrane matrix in the upper chamber whereas HGF $20 \mathrm{ng} / \mathrm{ml}$ (for hepatoma cells) or PDGF-BB $10 \mathrm{ng} / \mathrm{l}$ (for HSCs) was added to the lower chamber. (A) Representative example of migration of HepG2 cells (left), HuH7 cells (middle), and HSCs (right) through the pores of the membrane of a Boyden migration chamber. The top row corresponds to controls whereas the lower row shows the effect of addition of $10^{-9} \mathrm{~mol} / \mathrm{I} \mathrm{L}-797,591$, a specific SSTR1 agonist, to the upper chamber. Clearly, fewer cells migrated to the lower chamber in the presence of L-797,591. Original magnification $\times 200$. (B) Average number of cells which migrated to the lower Boyden chamber. Results are expressed as a percentage relative to controls normalised to 100\% (mean (SD)). The Mann-Whitney test was used to analyse differences between controls and treated groups: ${ }^{*} p<0,05,{ }^{* *} p<0.01$ compared with controls.

reason why SSTRs are upregulated during liver injury remains to be elucidated but it has been demonstrated in blood vessels and other tissues that injury, cytokines, growth factors, and somatostatin regulate SSTR gene expression. ${ }^{326}$ Noteworthy is the fact that interface HSCs clearly express different SSTRs whereas lobular HSCs express mainly SSTRI. This may emphasise a possible role for a SSTRI mediated decrease in portal hypertension via relaxation of HSCs. ${ }^{16}$
However, we must emphasise that the cirrhotic tissues examined in our study were from patients with HCC. Further studies need to be performed in cirrhotic tissue of patients without HCC to rule out a possible effect of HCC on expression of SSTRs.

The presence of SSTRs has been described in HCC. ${ }^{56}$ As measured by autoradiography, $41 \%$ of HCC were SSTR positive, predominantly subtype $2 .^{6}$ In agreement with 
previous studies, SSTR2 was expressed in two thirds of our studied samples. Again, both at the mRNA and protein levels, SSTRl and 2 were most apparent, with intermediate expression of SSTR3 and low expression of SSTR4 and 5. In some samples we found myofibroblasts or HSCs that double stained for SSTRs and $\alpha$-SMA. With RT-PCR and immunohistochemistry on isolated and cultured HepG2, HuH7, and HSCs, we were able to confirm our findings of SSTR expression in liver tissue.

It is clear from our own and other studies that there is considerable variation in expression of SSTRs in human HCC. The main question is, does activation of these receptors have antitumoral effects and, if so, through which receptor(s). It has been shown previously that antitumoral effects of somatostatin in other tumours are mediated directly by receptors present on the tumour cells resulting in growth arrest, apoptosis, or inhibition of migration and indirectly via inhibition of release of growth factors or cytokines, modulation of immune cells, and inhibition of neoangiogenesis. ${ }^{4} 2728$ The exact mechanism by which somatostatin could have an effect on progression of HCC remains to be elucidated. Previously, it has been shown in human hepatoma cell lines that somatostatin reduced proliferation of hepatoma cells only in the presence of insulin ${ }^{29}$ or insulin-like growth factor, ${ }^{11}$ which may be the reason why we did not observe any antiproliferative effect in our model. Using the same experimental set up in a study on hepatic fibrosis, equally we could not demonstrate any effect of somatostatin 14 on proliferation of HSCs (unpublished observations). The mechanism by which somatostatin reduces cell proliferation in hepatoma cells remains unresolved but it has been shown that octreotide induced insulin-like growth factor binding protein expression in human hepatoma cells, ${ }^{30}$ which decreases bioactivity of insulin-like growth factor, a well recognised mitogen for hepatoma cells. ${ }^{31}$

Apoptotic effects of somatostatin, attributed to SSTR2 and $3,{ }^{32}{ }^{33}$ have been described with octreotide, ${ }^{34}$ lanreotide, ${ }^{11}$ and a tumour selective somatostatin analogue TT-232. ${ }^{35}$ Using the TUNEL reaction, we were unable to show any significant SSTR2 or 3 induced apoptosis in any of the cell lines studied. As the TUNEL reaction preferentially labels DNA strand breaks generated during apoptosis, it allows discrimination of apoptosis from necrosis and from primary DNA breaks caused by cytotoxic drugs. This different experimental set up may explain the divergent results.

Migration, a key feature of malignant cells, was reduced via activation of SSTR subtype 1 in our study. Somatostatin may prevent cell migration and invasion in several ways. Firstly, it was demonstrated that somatostatin inhibited activation of Rho, the assembly of focal adhesions and actin stress fibres, and cell migration in response to both integrin and $G$ protein coupled receptor mediated signals. ${ }^{36}$ These effects were mediated through SSTR subtype 1. The Rho signalling pathway plays a critical role in tumour invasion and metastasis ${ }^{37}$ and has been shown to be essential for intrahepatic metastasis in human HCC. ${ }^{38}$ Moreover, a specific Rho kinase inhibitor, Y-27632, prevented Rho mediated cell migration of hepatoma cells ${ }^{39}$ as well as intrahepatic metastasis of HCC. ${ }^{40}$ Secondly, HGF, a very potent chemotactic factor for hepatoma cells, binds and activates a transmembrane receptor belonging to the receptor tyrosine kinase family. ${ }^{41}$ Phosphorylation of the receptor by HGF activates phosphatidylinositol (PI) 3-kinase, ultimately resulting in migration of hepatoma cells. ${ }^{42}$ All five SSTRs stimulate protein tyrosine phosphatase which inhibits the Ras-PI 3-kinase-Rac pathway by dephosphorylation of tyrosine kinase receptor. ${ }^{3}$ Finally, SSTR subtypes 1 and 2 are linked to $\mathrm{Ca}^{+2}$ and $\mathrm{K}^{+}$channels and influence $\left[\mathrm{Ca}^{+2}\right]_{\mathrm{i}}$ and thus cell contractility and motility. ${ }^{3}$
Although tumour cells are most important, other cell types present in and around tumours play a crucial role in tumour progression. Indeed, in addition to carcinoma cells, a stromal compartment, including extracellular matrix, blood vessels, and myofibroblasts, is present in HCC. The role of HSCs/ myofibroblasts in HCC is not completely elucidated but most observations suggest that they could facilitate tumour progression, probably by secretion of HGF. ${ }^{22}{ }^{43-45}$ We showed reduced migration of HSCs via SSTR1. It is thus conceivable that reduced migration of HSC results in decreased invasion of tumour cells.

From our in vitro observations it seems that somatostatin has no major inhibitory effect on tumour growth. It should be kept in mind however that in this study SSTR subtype specific agonists were used. It remains possible that activation of a combination of SSTRs is necessary to inhibit tumour growth or induce apoptosis. As stated above, addition of growth factors (for example, insulin) to the culture media could alter the results. Furthermore, in vivo effects might be different from in vitro observations. Indeed, in addition to direct effects on the tumour, indirect effects may be of importance. $^{27}$ Although somatostatin has antiangiogenic effects in some tumours, ${ }^{46}$ and HCC are highly vascularised, antiangiogenic effects of somatostatin in HCC have not been investigated to date. As mentioned above, octreotide suppressed hepatic expression and serum levels of insulin-like growth factor I and induced insulin-like growth factor binding protein. ${ }^{30} 47$ Finally, hyperinsulinaemia, which has been associated with accelerated growth of HCC, was decreased by octreotide, resulting in reduced growth rate of HCC. ${ }^{48}$

Clinical experience with somatostatin analogues is considerable and treatment is usually well tolerated, without major side effects. These are important considerations for the palliative treatment of inoperable HCC. However, maximal effort should be made to identify the optimal agonist(s) for maximal response. Using specific somatostatin agonists, we were unable to demonstrate any significant effect on proliferation and apoptosis in different cell lines. This could explain the marginal effect on tumour regression in most clinical studies. However, we showed reduced migration of HSCs and hepatoma cells via SSTRl. From our data, it seems that agonists of SSTRl could prevent intra- and extrahepatic metastasis of HCC. To date, no long acting SSTRl agonists have been tested in patients with HCC. Because somatostatin and analogues may have different effects in vivo, in vivo animal experiments with specific somatostatin analogues are awaited to confirm the in vitro data before initiating new randomised clinical trials in patients with advanced HCC.

\section{ACKNOWLEDGEMENTS}

This work was supported by Scientific Fund W. Gepts AZ-VUB, FWOV (Fonds voor Wetenschappelijk Onderzoek-Vlaanderen) grants No 1.5.618.98 and G.0068.00, OZR-VUB (Onderzoeksraad Vrije Universiteit Brussel) grants No 1963221120, OZR234 and OZR439, GoA-VUB grant 12, CIHR grant \#MT 10411, and MT-6196.

This article is in honour of Professor YC Patel (Division of Endocrinology and Metabolism, McGill University, Montreal, Canada) who devoted his career to somatostatin receptors but passed away during the completion of this study. We are grateful to Merck Research Laboratories, Rahway, NJ, USA for kindly providing the specific SSTR subtype agonists L-797,591, L-779,976, L-796,778, L-803,087, and L-817,818. We thank Professor C Balabaud (Service d'Hépato-gastroentérologie) and Professor J Saric (Service de Chirurgie Digestive), Hôpital Saint André, Bordeaux, for their contribution to the Bordeaux Liver Tumor Database. We are indebted to E Quartier (Diabetes Research Center, Free University of Brussels, Belgium) for sequencing and to JM Lazou (Laboratory for Molecular Liver Cell Biology, Free University of Brussels, Belgium) for excellent technical assistance. 


\section{Authors' affiliations}

H Reynaert*, Laboratory for Molecular Liver Cell Biology, Free University of Brussels (VUB), and Division of GastroenterologyHepatology, University Hospital, Free University of Brussels (VUB), Brussels, Belgium

K Rombouts*, Laboratory for Molecular Liver Cell Biology, Free University of Brussels (VUB), , Brussels, Belgium, and Dipartimento di Medicina Interna, Università degli Studi di Firenze, Firenze, Italy A Vandermonde, A Geerts, Laboratory for Molecular Liver Cell Biology, Free University of Brussels (VUB), Brussels, Belgium

D Urbain, Division of Gastroenterology-Hepatology, University Hospital, Free University of Brussels (VUB), Brussels, Belgium

U Kumar, Department of Medicine, Royal Victoria Hospital, McGill University, Montreal, Canada

P Bioulac-Sage, Groupe de Recherche pour I' Etude du Foie, INSERM E0362 and IFR 66, Université Victor Segalen, Bordeaux 2, France, and Pathology Department, University Hospital, Bordeaux, France

M Pinzani, Dipartimento di Medicina Interna, Università degli Studi di Firenze, Firenze, Italy

J Rosenbaum, Groupe de Recherche pour I' Ełude du Foie, INSERM

E0362 and IFR 66, Université Victor Segalen, Bordeaux 2, France

*H Reynaert and K Rombouts contributed equally to this study.

\section{REFERENCES}

1 El Serag HB, Mason AC, Key C. Trends in survival of patients with hepatocellular carcinoma between 1977 and 1996 in the United States. Hepatology 2001;33:62-5.

2 Befeler AS, Di Bisceglie AM. Hepatocellular carcinoma: diagnosis and treatment. Gastroenterology 2002;122:1609-19.

3 Patel YC. Somatostatin and its receptor family. Front Neuroendocrinol 1999;20:157-98.

4 Reubi JC, Schaer JC, Laissue JA, et al. Somatostatin receptors and their subtypes in human tumors and in peritumoral vessels. Metabolism 1996;45:39-41

5 Kouroumalis E, Skordilis $\mathrm{P}$, Thermos K, et al. Treatment of hepatocellular carcinoma with octreotide: a randomised controlled study. Gut 1998:42:442-7.

6 Reubi JC, Zimmermann A, Jonas S, et al. Regulatory peptide receptors in human hepatocellular carcinomas. Gut 1999;45:766-74.

7 Dimitroulopoulos D, Xinopoulos D, Tsamakidis K, et al. The role of sandostatin LAR in treating patients with advanced hepatocellular cancer. Hepatogastroenterology 2002:49:1245-50.

8 Samonakis DN, Moschandreas J, Arnaoutis T, et al. Treatment of hepatocellular carcinoma with long acting somatostatin analogues. Oncol Rep 2002;9:903-7.

9 Yuen MF, Poon RT, Lai CL, et al. A randomized placebo-controlled study of long-acting octreotide for the treatment of advanced hepatocellular carcinoma. Hepatology 2002;36:687-91.

10 Rabe C, Pilz T, Allgaier HP, et al. Clinical outcome of a cohort of 63 patients with hepatocellular carcinoma treated with octreotide. Z Gastroenterol 2002:40:395-400.

11 Raderer M, Hejna MH, Muller C, et al. Treatment of hepatocellular cancer with the long acting somatostatin analog lanreotide in vitro and in vivo. Int J Oncol 2000;16:1197-201

12 Allgaier HP, Becker G, Olschewski M, et al. Octreotide treatment in patients with advanced hepatocellular carcinoma: first results of the randomized placebo-controlled double blind Hector trial. Hepatology 2003;38(supp 1):760A.

13 Pinzani M, Failli $P$, Ruocco $C$, et al. Fat-storing cells as liver-specific pericytes Spatial dynamics of agonist-stimulated intracellular calcium transients. J Clin Invest 1992:90:642-6.

14 Kumar U, Sasi R, Suresh S, et al. Subtype-selective expression of the five somatostatin receptors (hSSTR1-5) in human pancreatic islet cells: a quantitative double-label immunohistochemical analysis. Diabetes 1999:48:77-85.

15 Niki T, Pekny M, Hellemans K, et al. Class VI intermediate filament protein nestin is induced during activation of rat hepatic stellate cells. Hepatology 1999;29:520-7.

16 Reynaert H, Vaeyens F, Qin H, et al. Somatostatin suppresses endothelin-1induced rat hepatic stellate cell contraction via somatostatin receptor subtype 1. Gastroenterology 2001;121:915-30.

17 Rombouts K, Niki T, Wielant A, et al. Effect of aldosterone on collagen steady state levels in primary and subcultured rat hepatic stellate cells. $J$ Hepatol 2001;34:230-8.

18 Rohrer SP, Birzin ET, Mosley RT, et al. Rapid identification of subtype-selective agonists of the somatostatin receptor through combinatorial chemistry. Science 1998;282:737-40.
19 Rohrer SP, Schaeffer JM. Identification and characterization of subtype selective somatostatin receptor agonists. J Physiol (Paris) 2000;94:211-15.

20 Rombouts K, Wielant A, Hellemans K, et al. Influence of aldosterone on collagen synthesis and proliferation of rat cardiac fibroblasts. Br J Pharmacol 2001; 134:224-32.

21 Marra F, Gentilini A, Pinzani M, et al. Phosphatidylinositol 3-kinase is required for platelet-derived growth factor's actions on hepatic stellate cells. Gastroenterology 1997; 112:1297-306.

22 Neaud V, Faouzi S, Guirouilh J, et al. Human hepatic myofibroblasts increase invasiveness of hepatocellular carcinoma cells: evidence for a role of hepatocyte growth factor. Hepatology 1997;26:1458-66.

23 Talme $T$, Ivanoff J, Hagglund $M$, et al. Somatostatin receptor (SSTR) expression and function in normal and leukaemic T-cells. Evidence for selective effects on adhesion to extracellular matrix components via SSTR2 and/or 3. Clin Exp Immunol 2001;125:71-9.

24 Yamada Y, Post SR, Wang K, et al. Cloning and functional characterization of a family of human and mouse somatostatin receptors expressed in brain, gastrointestinal tract, and kidney. Proc Natl Acad Sci U S A 1992;89:251-5.

25 Curtis SB, Hewett J, Yakubovitz S, et al. Somatostatin receptor subtype expression and function in human vascular tissue. Am J Physiol Heart Circ Physiol 2000;278:H1815-22.

26 Curtis SB, Chen JC, Winkelaar G, et al. Effect of endothelial and adventitial injury on somatostatin receptor expression. Surgery 2000;127:577-83.

27 Pollak MN, Schally AV. Mechanisms of antineoplastic action of somatostatin analogs. Proc Soc Exp Biol Med 1998;217:143-52.

28 Ferjoux G, Bousquet C, Cordelier P, et al. Signal transduction of somatostatin receptors negatively controlling cell proliferation. J Physiol Paris 2000;94:205-10.

29 Chou CK, Ho LT, Ting LP, et al. Selective suppression of insulin-induced proliferation of cultured human hepatoma cells by somatostatin. J Clin Invest 1987;79:175-8.

30 Ren SG, Ezzat S, Melmed S, et al. Somatostatin analog induces insulin-like growth factor binding protein-1 (IGFBP-1) expression in human hepatoma cells. Endocrinology 1992;131:2479-81.

31 Huynh H, Chow PK, Ooi LL, et al. A possible role for insulin-like growth factorbinding protein-3 autocrine/paracrine loops in controlling hepatocellular carcinoma cell proliferation. Cell Growth Differ 2002;13:115-22.

32 Guillermet J, Saint-Laurent N, Rochaix P, et al. Somatostatin receptor subtype 2 sensitizes human pancreatic cancer cells to death ligand-induced apoptosis. Proc Natl Acad Sci U S A 2003;100:155-60.

33 Sharma K, Patel YC, Srikant CB. Subtype selective induction of $p-53$ dependent apoptosis but not cell cycle arrest by human somatostatin receptor 3. Mol Endocrinol 1996;10:1688-96.

34 Chen X, Liu Z, Ai Z. Antineoplastic mechanism of octreotide action in human hepatoma. Chin Med J 2001;114:1167-70.

35 Diaconu CC, Szathmari M, Keri G, et al. Apoptosis is induced in both drugsensitive and multidrug-resistant hepatoma cells by somatostatin analogue TT232. Br J Cancer 1999;80:1197-203.

36 Buchan AM, Lin CY, Choi J, et al. Somatostatin, acting at receptor subtype 1, inhibits rho activity, the assembly of actin stress fibers, and cell migration. J Biol Chem 2002;277:28431-8.

37 Schmitz AA, Govek EE, Bottner B, et al. Rho GTPases: signaling, migration, and invasion. Exp Cell Res 2000;261:1-12

38 Genda T, Sakamoto M, Ichida T, et al. Cell motility mediated by rho and Rhoassociated protein kinase plays a critical role in intrahepatic metastasis of human hepatocellular carcinoma. Hepatology 1999;30:1027-36.

39 Itoh K, Yoshioka K, Akedo H, et al. An essential part for Rho-associated kinase in the transcellular invasion of fumor cells. Nat Med 1999:5:221-5.

40 Takamura M, Sakamoto M, Genda T, et al. Inhibition of intrahepatic metastasis of human hepatocellular carcinoma by Rho-associated protein kinase inhibitor Y-27632. Hepatology 2001;33:577-81.

41 Stuart KA, Riordan SM, Lidder S, et al. Hepatocyte growth factor/scatter factor-induced intracellular signalling. Int J Exp Pathol 2000;81:17-30.

42 Nakanishi K, Fujimoto J, Ueki T, et al. Hepatocyte growth factor promotes migration of human hepatocellular carcinoma via phosphatidylinositol 3kinase. Clin Exp Metastasis 1999; 17:507-14.

43 Faouzi S, Le Bail B, Neaud V, et al. Myofibroblasts are responsible for collagen synthesis in the stroma of human hepatocellular carcinoma: an in vivo and in vitro study. J Hepatol 1999;30:275-84.

44 Theret K, Musso O, Turlin B, et al. Increased extracellular matrix remodeling is associated with tumor progression in human hepatocellular carcinomas. Hepatology $2001 ; 34: 82-8$.

45 Monvoisin A, Neaud V, De Ledinghen V, et al. Direct evidence that hepatocyte growth factor-induced invasion of hepatocellular carcinoma cells is mediated by urokinase. J Hepatol 1999;30:511-18.

46 Albini A, Florio T, Giunciuglio D, et al. Somatostatin controls Kaposi's sarcoma tumor growth through inhibition of angiogenesis. FASEB $J$ 1999:13:647-55

47 Huynh H, Pollak M. Enhancement of tamoxifen-induced suppression of insulin-like growth factor I gene expression and serum level by a somatostatin analogue. Biochem Biophys Res Commun 1994;203:253-9.

48 Saito K, Inoue S, Saito T, et al. Augmentation effect of postprandial hyperinsulinaemia on growth of human hepatocellular carcinoma. Gut 2002;51:100-4. 